\title{
USOS DO CONECTOR EXCETO: um panorama sob a perspectiva da linguística funcional centrada no uso
}

Ivo da Costa do Rosário

(UFF)

https://orcid.org/0000-0003-1315-6787

Fabiana Felix Duarte Moreira

(UFF)

https://orcid.org/0000-0003-2980-2261

\section{RESUMO}

O objetivo deste trabalho é traçar um panorama dos usos do conector exceto (e formas compostas - exceto que, exceto se, exceto quando), seus principais traços morfossintáticos e valores semânticos. A análise do objeto se dá à luz da perspectiva da Linguística Funcional Centrada no Uso, adotando-se os pressupostos teóricos de CROFT (2001), GOLDBERG (1995, 2006), GOLDERG; CASENHISER (2010), KORTMANN (1997) e TROUSDALE (2008). Com base em um corpus de língua real do português brasileiro, atestamos sete diferentes padrões para as construções de exceção instanciadas pelo conector exceto: três padrões não oracionais (exceto $+\mathrm{SN}$, exceto $+\mathrm{SPrep}$ e exceto $+\mathrm{SAdv}$ ) e quatro oracionais (exceto + quando, exceto + se, exceto + que e exceto + infinitivo $)$. Com base nessas afirmações, postulamos a existência e a produtividade das construções de exceção no português do Brasil.

PALAVRAS CHAVE: Hipotaxe. Exceção. Exceto. 


\section{USES OF THE CONECTOR EXCEPT: A PANORAMA UNDER THE PERSPECTIVE OF USAGE-BASED FUNCTIONAL LINGUISTICS}

\section{ABSTRACT}

The objective of this work is to outline the uses of the connector except (and compound forms - except that, except if, except when), its main morphosyntactic features and semantic values. The analysis of the subject takes place in the perspective of UsageBased Functional Linguistics, adopting the theoretical assumptions of CROFT (2001), GOLDBERG (1995, 2006), GOLDERG; CASENHISER (2010), KORTMANN (1997) and TROUSDALE (2008). Based on a real language corpus of Brazilian Portuguese, we attested seven different patterns for the exception construction instantiated by the connector except: three non-clausal patterns (except $+\mathrm{NP}$, except + preposition and except + adverbial $)$ and four clausal patterns (except + when, except + if, except + that and except + infinitive). Based on these statements, we postulate the existence and productivity of constructions of exception in Brazilian Portuguese.

KEY WORDS: Hypotaxis. Exception. Except.

\section{Considerações iniciais}

A Nomenclatura Gramatical Brasileira, que serve de base para a maioria das gramáticas normativas produzidas em nosso país, não contempla as orações de exceção, provocando, assim, um verdadeiro hiato na descrição das chamadas orações adverbiais. Apesar disso, alguns poucos autores (ROCHA LIMA, 1999, p. 263) mencionam as orações de exceção em seus compêndios, normalmente com uma descrição muito breve ou restrita a um único exemplo.

De modo inverso, essa não é a postura adotada por muitos pesquisadores estrangeiros. Por exemplo, KORTMANN (1997, p. 84-87), após realizar um grande estudo tipológico que envolveu dezenas de línguas europeias, propôs uma classificação das 32 relações interclausais encon- 
tradas, agrupando-as em quatro grandes grupos: tempo, CCC (causa, condição, concessão) e modo, além de um quarto grupo híbrido, chamado por ele de outros (as). No grupo CCC, o autor arrola as orações de exceção/ restrição, em acepção muito semelhante à que é admitida neste trabalho.

Diante da quase inexistência de investigações acerca desse tipo de construção linguística no português do Brasil (PB), objetivamos, por meio deste trabalho, fornecer evidências de que o conector exceto, combinado ou não com outros itens, é produtivo e instancia as chamadas construções de exceção, tanto oracionais quanto não oracionais. Portanto, urge uma descrição mais centrada de seus usos e uma investigação mais detida de seu comportamento morfossintático. Para fins ilustrativos, vejamos uma instanciação dessa construção no nível oracional:

(01) Famosos e anônimos aproveitam a madrugada para trabalhar ou realizar qualquer outro tipo de atividade, exceto dormir. Em 'Calada Noite', série que estreia hoje, às $23 \mathrm{~h} 30$, no GNT, Sarah Oliveira vai conversar com pessoas que têm uma relação especial com a noite. A primeira convidada ilustre é a atriz Patrícia Pillar, que revela seus hábitos noturnos. (http://odia.ig.com.br/diversao/televisao/2015-03-04/ programa-apresenta-famosos-e-anonimos-que-preferem-a-madrugada.html, acesso em 21/08/2015).

No dado (01), exceto dormir configura-se como um exemplo de construção oracional de exceção, instanciada pelo conector exceto. Dormir é uma ação deslocada das demais (trabalhar ou realizar qualquer outro tipo de atividade), ganhando considerável relevo informacional. Sua forma infinitiva atesta a existência da construção de exceção no plano oracional.

Além do conector exceto, em sua forma simples, que já conta com alguns (mas mínimos) registros em nossas gramáticas, este trabalho também tem como objetivo investigar outras configurações da construção de exceção. Assim, nosso alvo de análise também contempla construções formadas por exceto que, exceto se e exceto quando, que, acreditamos, são estratégias de veiculação de conteúdos semânticos aparentados, mas, ao mesmo tempo, diferenciados, se comparados ao mais prototípico exceto, conector simples.

Para esta análise, foi feita uma busca do elemento exceto em textos publicados online no portal O Dia (http://odia.ig.com.br). Foram coletadas cem ocorrências desse conector em textos publicados entre 2010 e 2015 nos mais variados gêneros jornalísticos, o que evidencia a vitalidade 
dos usos sincrônicos desse item na variedade brasileira da língua portuguesa.

Na seção seguinte, expomos uma síntese dos postulados centrais da Linguística Funcional Centrada no Uso, que foi eleita a base teórica para este trabalho, devido ao seu compromisso com a análise de dados reais de língua. Em seguida, traçamos uma breve revisão da bibliografia acerca do item exceto em algumas obras de viés gramatical e/ou linguístico. Por fim, apresentamos os procedimentos metodológicos adotados e a análise de dados propriamente dita, seguida das considerações finais e referências bibliográficas.

\section{Linguística Funcional Centrada no Uso}

A Linguística Funcional Centrada no Uso (doravante, LFCU) está consubstanciada no "casamento teórico" da Linguística Funcional de vertente norte-americana com a Gramática de Construções, especialmente na linha de GOLDBERG (1995, 2006) e CROFT (2001). A aproximação dessas duas vertentes tem possibilitado importantes investigações das línguas naturais pelo prisma das construções.

De acordo com GOLDBERG (1995, p. 1) e GOLDERG; CASENHISER (2010, p. 4), construções são "correspondências de forma-significado" que funcionam como unidades básicas e centrais da língua, ou, nos termos de Trousdale (2008, p. 6), são unidades simbólicas convencionais (conventional symbolic unit) que operam em diferentes níveis da gramática.

Considerando a gramática como uma representação cognitiva da experiência linguística dos indivíduos, a LFCU incorpora a semântica e a pragmática à análise das construções, alargando seus interesses para além do plano morfossintático. De acordo com a LFCU, a língua é um sistema a serviço das necessidades intercomunicativas do usuário, motivada por fatores linguísticos e extralinguísticos (MARTELOTTA, 2011; ROSÁRIO, 2015; ROSÁRIO, OLIVEIRA, 2016). Nessa perspectiva teórica, o foco são os padrões linguísticos em seus contextos de uso.

De fato, o uso é considerado o grande motor da mudança linguística. É justamente na interação verbal que os significados são negociados e as alterações na língua são instauradas. Nesses processos, atuam princípios cognitivos e interacionais, em um complexo mosaico de atividades integradas. Portanto, ao mesmo tempo em que há aspectos estáveis, também é possível verificar diversas instabilidades que acomodam e desaco- 
modam continuamente o sistema linguístico. Assim, um princípio muito caro aos que adotam a LFCU é que a gramática da língua está em um permanente movimento dinâmico, em uma acepção muito próxima à clássica formulação de gramática emergente, defendida por HOPPER (1991).

Em síntese, é possível defender que a LFCU "trabalha na interface entre uso e estrutura, considerando a emergência e a regularização de padrões linguísticos na interação verbal" (CUNHA; BISPO; SILVA, 2013, p. 18). Nesse sentido, a LFCU vai além das perspectivas clássicas de gramaticalização, visto que lança luz não só sobre aspectos funcionais, mas também sobre aspectos formais do fenômeno linguístico. Ademais, o plano de análise não está mais concentrado apenas no item linguístico, mas em uma entidade um pouco mais ampla e complexa, ou seja, no campo da construção, como já foi definido nesta seção.

A partir desse modelo teórico, os estudos funcionalistas passaram a adotar uma visão mais abrangente dos fenômenos linguísticos, englobando aspectos fonológicos, morfológicos e sintáticos (plano da forma), bem como aspectos semânticos, pragmáticos e discursivos (plano do significado). Julgamos que essa abordagem apresenta-se como modelo teórico apropriado para a investigação do conector exceto (e compostos) em seus usos linguísticos reais.

\section{0 conector EXCETO}

Não há um consenso sobre qual seria a classificação morfossintática do conector exceto, haja vista sua grande versatilidade. Segundo o dicionário PRIBERAM, exceto pode ser uma preposição, um advérbio, um adjetivo ou até mesmo um substantivo masculino. Assim, verificamos que a classificação do item é pouco precisa. Para ampliar a discussão, faz-se necessário, portanto, explorar as classificações apresentadas pelos gramáticos e linguistas, por meio de uma revisão da literatura sobre o tema.

CUNHA e CINTRA (2001, p. 556) classificam exceto como preposição acidental, por pertencer, normalmente, a outra classe, no caso, particípio e advérbio, mas funcionar às vezes como preposição. O dado (02) a seguir coaduna-se bem com a visão descritiva de CUNHA e CINTRA (2001, p. 556), visto que o item exceto, de fato, comporta-se como um item preposicional. Vejamos:

(02) Lexa ficou seis meses se preparando antes de fazer o primeiro show, ou seja, antes de gerar a primeira receita. Nesse caso, todos os custos com essa preparação que engloba academia, personal, aulas de 
inglês, piano, coach de TV, produção do show, contratação de músicos, ensaios, moradia, media training, mudanças de visual, fono, canto, etc. são planejados e retirados da verba de investimento de carreira do produto Lexa. Portanto, no primeiro ano de contrato nenhum sócio faz retirada, exceto Lexa, que tem além de todos os custos pagos, uma ajuda de custo mensal. (http://blogs.odia.ig.com.br/leodias/2015/08/24/lexa-recebe-ajuda-de-custo-de-r-3-mil-mensais/, acesso em 29/08/2015)

Nesse exemplo (02), o item exceto exibe comportamento preposicional, pois rege elemento nominal (exceto Lexa). Logo, como já afirmamos, de fato, esse é um uso contemplado pelas gramáticas e igualmente atestado em dados de língua real. Sem dúvida, é um uso contemporâneo, em produtividade na variedade brasileira do português.

BECHARA (2015, p. 316) também inclui exceto no rol das preposições acidentais. $\mathrm{O}$ autor acrescenta que só as preposições essenciais podem ser acompanhadas de formas tônicas dos pronomes oblíquos. $\mathrm{O}$ autor apresenta um exemplo com pronome reto "Exceto eu, todos foram contemplados". No corpus, não encontramos nenhum dado com forma tônica de pronome oblíquo, corroborando o que ele havia afirmado sobre o fato de exceto não ser uma preposição essencial, e sim acidental.

No exemplo (03), a seguir, a partícula exceto introduz o pronome reto ele. Trata-se de um exemplo muito semelhante ao fornecido por BECHARA (2015, p. 316). Assim, esse "lugar" da partícula exceto é confirmado tanto pelo gramático quanto pelos dados reais de língua em uso do PB:

(03) Jonatas Faro, lindo, explicava o mico que foi o quadro 'Artista Completão'. Exceto ele, lógico. Ah, e como não poderia faltar? Ela foi a última a chegar, mas tinha que causar: Susana Vieira. Cumprimentou a todos com beijinhos e, na hora do "gravando", baixou a Susana de sempre. Depois de ouvir elogios como "diva", "estrela", ela solta: "Você diz isso para todas...". Ledo engano! (http://blogs.odia.ig.com. br/leodias/2014 /05/21/saiba-o-que-ninguem-contou-sobre-a-estreia-de-crazy-for-you/. Acesso em 29/08/2015)

MOURA NEVES (2011, p. 735-736) reitera a classificação de exceto como uma preposição acidental que introduz sintagma nominal ou oração infinitiva, estabelecendo uma relação semântica de exclusão. A autora, portanto, dá um passo adicional na descrição desse elemento linguístico, visto que aborda seu uso na função de conectivo interoracional.

Por sua vez, CASTILHO (2014, p. 542 e 575), ao listar catorze tipos de advérbios, inclui os de exclusão, em oposição aos de inclusão. 
Ele acrescenta que esses advérbios (de exclusão e de inclusão) têm um substantivo como escopo, expresso ou não, atuando como especificador de um sintagma nominal.

Com relação ao espanhol, a Nueva Gramática de la Lengua Española (2010, p. 622) admite exceto como uma das conjunções que denotam exceção. Nessa gramática, afirma-se que exceto costuma ser interpretado em relação a alguma expressão quantitativa universal, como todo(s), nenhum, nada, sempre, nunca ou plurais definidos, para introduzir algo que não faz parte desse conjunto. Vejamos mais um dado:

(04) "É muito importante para nós mostrar que temos o ritmo para ser os primeiros na frente de todos, exceto a Mercedes. Amanhã não será fácil, mas estamos preparados e será uma corrida empolgante", comentou Massa, que disse ser "fantástico" ver as duas Williams na segunda fila. (http://odia.ig.com.br/esporte/2015-07-04/massa-vibra-por-estar-atras-apenas-da-mercedes-e-espera-corrida-empolgante.html, acesso em 29/08/2015)

Nesse exemplo (04), constatamos o uso de exceto, em língua portuguesa, cumprindo a função indicada pela Nueva Gramática de la Lengua Española (2010, p. 622). A expressão exceto a Mercedes cumpre a função de deslocar um elemento do conjunto indicado pelo pronome indefinido todos. Em outras palavras, no exemplo (04), a expressão quantitativa universal é todos. O elemento que não faz parte desse conjunto é Mercedes. Esse arranjo sintático-semântico é possível, graças ao uso da partícula de exclusão exceto, classificada como conjunção ${ }^{1}$.

Esta seção ilustrou a multifuncionalidade do elemento gramatical exceto em língua portuguesa. Gramáticos e linguistas defendem que exceto pode ser ou preposição ou advérbio ou conjunção. Os dados reais de língua escrita do português brasileiro comprovam essa versatilidade. $\mathrm{Na}$ próxima seção, vamos apresentar mais dados coletados de nosso corpus, de forma mais orgânica e sistemática. Também será possível aferir a frequência de uso de cada construção que instancia a partícula exceto, também em suas formas compostas (exceto que, exceto se e exceto quando).

\footnotetext{
${ }^{1}$ Os limites entre conjunções e preposições, bem como os de outras categorias gramaticais, são bastante fluidos e controversos. Essa é uma questão de grande importância, mas, como excederia os objetivos deste artigo e demandaria um espaço maior para discussão, optamos por não explorá-la neste trabalho. Portanto, ao fazermos referência ao item exceto, que é o foco deste trabalho, referimo-lo como conector.
} 


\section{Procedimentos metodológicos e análise de dados}

O corpus selecionado para esta pesquisa é composto por diversas matérias publicadas no portal online do Jornal O Dia, gratuitamente disponível na internet. Como metodologia de trabalho, com base no mecanismo de busca eletrônica disponibilizado pelo site Google, decidimos analisar ocorrências de exceto, colhidas de 2010 a 2015. Dessa forma, atestamos os usos contemporâneos do fenômeno linguístico em estudo na variedade brasileira da língua portuguesa, em seus usos canônicos.

As ocorrências utilizadas para este estudo receberam um tratamento quantitativo, mas especialmente qualitativo. A partir das análises realizadas, foi possível postular a existência de sete padrões construcionais de exceto: três oracionais e quatro não oracionais. Nas seções seguintes, traçamos um panorama dos usos desse conector, com base na tabela 1, a seguir:

Tabela 1 - Padrões construcionais de exceto

\begin{tabular}{|l|l|r|}
\hline \multicolumn{2}{|l|}{ Padrões construcionais } \\
\hline \multirow{4}{*}{ Não oracionais } & Exceto + SN & 44 \\
\cline { 2 - 3 } & Exceto + SPrep & 23 \\
\cline { 2 - 3 } & Exceto + SAdv & 2 \\
\cline { 2 - 3 } & Subtotal & 69 \\
\hline \multirow{4}{*}{ Oracionais } & Exceto + quando & 18 \\
\cline { 2 - 3 } & Exceto + se & 3 \\
\cline { 2 - 3 } & Exceto + que & 3 \\
\cline { 2 - 3 } & Exceto + infinitivo & 31 \\
\cline { 2 - 3 } & Subtotal & 100 \\
\hline \multirow{5}{*}{} & Total de dados & \\
& &
\end{tabular}

A tabela 1 demonstra quantitativamente os usos do conector exceto em sete diferentes configurações morfossintáticas. Os usos não oracionais da construção de exceção são codificados pelo uso de exceto $+\mathrm{SN}$, exceto + SPrep ou exceto + SAdv, como será exemplificado a seguir. Vale destacar que o uso de exceto seguido de $\mathrm{SN}$ mostrou-se como o mais frequente 
(44 dados), corroborando a posição de diversos gramáticos e linguistas quanto ao seu papel de preposição acidental, visto que rege nome.

Os usos oracionais contam com 31 ocorrências. Nos três primeiros types, a partícula exceto vem acompanhada de outro conectivo mais básico (quando, se e que), mais verbo na forma finita. No último type atestado, o conector exceto é utilizado seguido de verbo no infinitivo. Nessa forma infinita, apenas três dados foram detectados. Em nossa amostra, não foram encontradas construções oracionais de exceção instanciadas pelo gerúndio nem pelo particípio.

Feitas essas observações gerais, vejamos cada um dos sete padrões construcionais atestados no corpus. Iniciamos a análise mais pormenorizada pelas construções não oracionais. Em seguida, passamos à investigação das construções oracionais.

\subsection{Construções não oracionais}

As construções não oracionais constituem três padrões encontrados nos dados: exceto $+S N$, exceto $+S$ Prep e exceto $+S A d v$. Por meio da análise da tabela 1 , fica muito claro que a frequência de uso de cada um dos três padrões é bastante distinta. Vamos analisar cada padrão em particular, pela ordem de frequência.

Como já foi afirmado anteriormente, exceto $+S N$ é a configuração formal mais comum no que diz respeito ao uso da partícula exceto, totalizando $44 \%$ das ocorrências. Dessas, $40 \%$ têm um substantivo como seu especificador expresso, como em (05). Apenas em 4\% dos casos o substantivo não está expresso, como podemos observar em (06), uma vez que o especificador obras havia sido citado anteriormente.

(05) Em artesanato, os cursos oferecidos são: patchwork, pintura em tecido, pintura em tela, escultura em argila e biscuit. Exceto o curso de escultura em argila, no qual o aluno deverá ter idade mínima de 7 anos, nos demais a faixa etária é 18 anos. (http://odia.ig.com.br/odiabaixada/2014-12-15/estao-abertas-as-inscricoes-para-os-cursos-da-casa-de-cultura-de-itaguai.html, acesso em 29/08/2015)

(06) Além das promessas de aumentar os terminais do BRT Santa Cruz e Alvorada, a Secretaria Municipal de Obras (SMO) divulgou que há estudos para ampliar as estações Magarça, Mato Alto e Curral Falso, do Transoeste, e transformá-las em terminais. As obras, que visam a amenizar os efeitos da superlotação, ainda não têm prazo para ocorrer, exceto a do Alvorada. (http://odia.ig.com.br/noticia/odia-no- 
-coletivo/2015-08-18/prefeitura-anuncia-ampliacao-de-estacoes-do-brt-transoeste.html, acesso em 29/08/2015)

Vale destacar que também foram encontrados, no corpus, quatro casos de exceto $+\mathrm{SN}$ em que o especificador do sintagma nominal é um pronome. Além de (03), visto anteriormente, que tem como escopo um pronome reto, temos mais três dados em que o escopo é um pronome demonstrativo, como em (07):

(07) "Estou disposto a conversar com aqueles extraviados que optaram por posições separatistas. Exceto, é claro, aqueles que se envolveram em atos de terrorismo, assassinato ou tortura", disse o presidente, que tomou posse no dia 7 de junho apoiado por líderes ocidentais. (http:// odia.ig.com.br/noticia/mundoeciencia/2014-06-23/ucrania-apresenta-plano-de-paz-para-o-leste-separatista.html, acesso em 29/08/2015).

Tanto em (06) quanto em (07), o conector exceto também cumpre função anafórica. Em (06), o trecho "exceto a do Alvorada" remete o leitor a uma porção textual anterior que indica o referente obras. Em (07), isso fica ainda mais explícito por meio do uso do demonstrativo que, por natureza, serve para apontar elementos citados. Esse é um dos traços do conector exceto: destacar uma parte, focalizando-a, em relação ao todo.

Após essa breve apresentação de exceto $+\mathrm{SN}$, passemos à análise do padrão construcional constituído por exceto + SPrep. No corpus, foram encontradas 23 ocorrências desse padrão. Em alguns momentos, o sintagma preposicionado tem valor circunstancial, em outros, não. Dentre esses 23 dados, há 7 com SPrep não circunstancial, como o dado (08):

(08) O Instituto Nacional do Seguro Social (INSS) não reconhece a desaposentação e defende a ilegalidade da revisão, de acordo com o Artigo 18 da Lei 9.528/97. "O aposentado pelo Regime Geral de Previdência Social que permanecer em atividade sujeita a esse regime, ou a ele retornar, não fará jus à prestação alguma da Previdência Social, em decorrência do exercício da atividade, exceto ao salário-família e à reabilitação profissional, quando empregado." (http://odia.ig.com.br/ noticia/economia/2014-10-09/stf-da-sequencia-a-julgamento-sobre-desaposentacao.html, acesso em 29/08/2015)

Em (08), a presença do SPrep se deve à regência da expressão anterior "fará jus". "Fazer jus" requer a preposição $a$ em seu complemento, como ocorre em dois dados do corpus selecionados para esta pesquisa. Em (09), o SPrep é formado pela preposição essencial para + os beneficiários (Reino Unido e Irlanda), excluindo-os do todo. Trata- 
-se, também, de um uso não circunstancial, verificado em mais quatro ocorrências.

(09) Os interessados em fazer viagens curtas, até três meses, para os países da União Europeia ficarão livres da necessidade de visto. Um acordo entre o governo do Brasil e a União Europeia determina a isenção do documento, exceto para o Reino Unido e a Irlanda. A medida vale para 25 países. Porém, unilateralmente, cada país poderá romper o acordo. As negociações já existentes permanecem em vigência. (http:// odia.ig.com.br/portal/brasil/brasileiros-j\%C3\%A1-podem-viajar-para-europa-sem-precisar-de-visto-1.499730, acesso em 29/08/2015)

Quanto aos sintagmas preposicionados circunstanciais junto ao conector exceto, foram coletadas 16 ocorrências. Em 10 dessas ocorrências, o SPrep indica espaço, como no dado (10). Em outras 5 ocorrências, a noção de tempo é veiculada, como em (11).

(10) Nesta sexta-feira (6), ar seco predomina sobre a maior parte do Sul do Brasil. Exceto no leste de Santa Catarina, inclusive em Florianópolis, e em Paranaguá, onde o sol aparece fraco entre algumas nuvens, que se formam devido aos ventos úmidos que sopram do oceano. Nas demais áreas, o sol aparece mais forte e a temperatura entra em elevação. De acordo com os meteorologistas da Climatempo, não há previsão de chuva em toda a região. (http://odia.ig.com.br/noticia/brasil/2013-09-06/feriado-de-7-de-setembro-deve-ter-sol-calor-e-baixa-umidade-no-interior-do-pais.html, acesso em 29/08/2015)

(11) Há poucos momentos em que o lado íntimo do artista é explorado. $\mathrm{Na}$ maioria das vezes que ele dá um depoimento, a câmera insiste em closes ou apenas o filma de costas. Exceto no momento em que Cauby fala abertamente sobre sua sexualidade e conta que já transou com homens. No mais, o longa se limita a outros depoimentos — de fãs, artistas e especialistas - pouco explorados na montagem. (http://odia. ig.com.br/diversao/2015-05-28/cauby---comecaria-tudo-outra-vez-tem-boas-ideias-perdidas-na-pratica.html, acesso em 29/08/2015)

Em (10) e em (11), as relações semânticas de espaço e tempo, respectivamente, não estão somente no SPrep subsequente ao exceto, mas em todo o trecho informado. Os frames de espaço e tempo são ativados por várias expressões ao longo do parágrafo. Em (10), as expressões locativas "sul do Brasil", "leste de Santa Catarina", "Florianópolis", "Paranaguá", "nas demais áreas" e "em toda região", por exemplo, contribuem para a semântica espacial desse token. Já em (11), temos "na maioria das 
vezes" e "momento" como expressões temporais que contribuem que esse conteúdo semântico.

Já em (12), temos o único dado encontrado no corpus com SPrep junto ao exceto que exprime uma relação semântica de causa, evidenciando mais uma possibilidade de seus usos. Essa relação semântica se aproxima do grupo CCC classificado por KORTMANN (1997):

(12) Exceto pelo fato de estarem ambos mortos, parece difícil encontrar algo que aproxime Mandela e Chávez? Não para o governo Maduro, homem que já recebeu mensagens do líder bolivariano até por meio de pássaros. Nesta quarta-feira, o vice-presidente Jorge Arreaza inaugurou um busto de Chavez ao lado de outro de Mandela em uma praça Diego Ibarra, no centro de Caracas. (http://odia.ig.com.br/ noticia/mundoeciencia/2014-01-22/vice-de-nicolas-maduro-inaugura-busto-em-homenagem-a-hugo-chavez-ao-lado-de-nelson-mandela. html, acesso em 29/08/2015)

Também é importante observar que essa é única ocorrência de nosso corpus em que exceto está anteposto ao seu referente. Nesse caso, é provável que a intenção do falante seja orientar o ouvinte para a informação seguinte. A anteposição decorre de uma função estritamente discursiva da língua (DECAT, 2001, p. 7). De fato, de acordo com GIVÓN (1993, p. 6), a anteposição "pode ser vista como um dispositivo de reorientação temática". Estabelece a coerência em uma fronteira temática, como ocorre no dado (12).

Apesar de não previsto pelos compêndios, o conector exceto também pode vir precedido de um SAdv, como podemos observar em (13) e (14), em que, no primeiro, o SAdv indica uma circunstância de tempo, e, no segundo, de assunto:

(13) Na parte religiosa em homenagem a São João, foram programadas missas todos os dias às $19 \mathrm{~h}$, exceto hoje e no próximo domingo, quando serão às $18 \mathrm{~h}$. Amanhã, dia do padroeiro, elas serão celebradas às 8h, 10h e 18h. (http://odia.ig.com.br/odiabaixada/2013-06-23/cidades-festejam-padroeiros.html, acesso em 29/08/2015)

(14) Caro Felipe, não perca tempo. Você já deveria estar com tudo comprado, ou pelo menos programado. Exceto quanto a aquisição dos dólares, que deve ser feita aos poucos e nas oportunidades. Mas os demais itens já deveriam estar pelo menos reservados. (http://odia. ig.com.br/noticia/economia/2014-09-19/sucesso-nas-compras-planeje-a-viagem-com-boa-antecedencia.html, acesso em 29/08/2015) 
Após análise de alguns dados representativos da construção de exceção não oracional, em que a semântica de exceção é normalmente "pura", ou seja, sem amálgama com outros matizes de significado, vejamos algumas ocorrências do uso de exceto em construções oracionais que, em sua totalidade, somam 31 dados coletados em nosso corpus de pesquisa.

\subsection{Construções oracionais}

As construções oracionais constituem quatro padrões encontrados nos dados: exceto + quando, exceto + que e exceto + se, além de exceto + infinitivo. São quatro distintas configurações morfossintáticas acompanhadas de valores semânticos igualmente distintos. Defendemos que os 31 dados, nesta configuração, atestam a existência e a produtividade de construções hipotáticas de exceção no português do Brasil.

Autores tradicionais não registram o uso de exceto quando. Entretanto, esse conector somou $18 \%$ das ocorrências, tendo sido o mais frequente dentre os padrões construcionais oracionais estudados.

Apesar de quando ter tradicionalmente um sentido de tempo, ao unir-se a exceto, adquire também um sentido condicional. BECHARA (2015, p. 342) prevê que "em algumas construções, se pode alterar o sentido originário do advérbio, motivado pelos significados dos lexemas que entram na oração e por uma interpretação suplementar, contextual, do falante, calcada na sua experiência de mundo". É o que acontece com o quando unido a exceto:

(15) A lei classifica como "ilegítimo" o uso de arma de fogo contra pessoa desarmada e veículo que desrespeite bloqueio policial em via pública, exceto quando representarem risco de morte ou lesão aos agentes ou a terceiros. (http://odia.ig.com.br/noticia/economia/2014-12-25/ agentes-de-seguranca-publica-terao-novas-regras-para-uso-de-armas. html, acesso em 20/08/2015)

O uso do conector exceto quando junto ao verbo no subjuntivo "representarem", de fato, veicula uma noção de condicionalidade. Contudo, trata-se de uma condicionalidade negativa. Afinal, a sentença com exceto quando poderia ser parafraseada por "A lei classifica como 'ilegítimo' o uso de arma de fogo contra pessoa desarmada e veículo que desrespeite bloqueio policial em via pública, SE NÃO representarem risco de morte ou lesão aos agentes ou a terceiros".

Essa nova semântica de condicionalidade negativa é um argumento favorável ao reconhecimento do conector exceto quando (conector com- 
plexo), e não exceto + quando (de natureza mais composicional). Defendemos, de fato, que o conector em foco perde considerável composicionalidade de suas partes a partir do momento em que veicula uma semântica mais unificada (exceção + tempo $>$ condicionalidade negativa).

Entretanto, apesar de a paráfrase de exceto quando ser possível por se não, cabe um questionamento: Qual teria sido a motivação para que o falante utilizasse um conector bem mais complexo (exceto quando) para a veiculação de um conteúdo condicional, se esse mesmo conteúdo poderia ter sido transmitido por meio de se não?

A provável resposta está na questão da intersubjetividade. O uso de exceto quando certamente imprime ao discurso uma carga mais expressiva. A intersubjetividade consiste justamente na utilização de recursos linguísticos novos para a atuação sobre o interlocutor, com vistas à sua adesão ou anuência (cf. ROSÁRIO, 2012). Esse processo conduz a um verdadeiro reforço de informatividade (cf. CUENCA; HILFERTY, 1999, p. 169), baseado em um processo metonímico de caráter inferencial. Essa necessidade discursiva pode funcionar como um verdadeiro motor para o aparecimento de novas formas gramaticais, o que é provável com relação a exceto quando.

Com relação ao conector exceto se, ROCHA LIMA (1999), CUNHA e CINTRA (2001) e BECHARA (2015) não o abordam em seus compêndios. MOURA NEVES (2001, p. 18), por outro lado, admite a existência desse elemento de ligação, que é marcado por uma circunstância condicional. Nesse caso, temos uma construção que amalgama dois matizes semânticos: exceção e condição. Vejamos:

(16) O projeto estabelece ainda que a condenação criminal não implica a perda do poder familiar, exceto se o pai ou a mãe tiver sido condenado por crime doloso praticado contra o próprio filho ou filha. Mesmo assim, nas hipóteses em que seja possível a perda do poder familiar, o projeto estabelece que os pais presos devem ser citados pessoalmente. (http://odia.ig.com.br/noticia/brasil/2014-03-18/senado-aprova-projeto-para-convivencia-de-criancas-com-pais-presos.html, acesso em 20/08/2015)

Em (16), junto ao conector exceto se, temos verbo no subjuntivo, confirmando a presença da semântica condicional junto à de exceção. A união do matiz condicional a outras noções semânticas é um fato largamente atestado em diversas pesquisas empíricas. Por exemplo, ROSÁRIO (2012) investigou, dentre outros conectivos, os usos funcionais 
de mesmo se, que adjunge as ideias de concessão e condição. Essa ideia de aproximação das relações semânticas de causa, concessão e condição também é proposta por KORTMANN (1997).

Agora cabem algumas reflexões sobre o conector exceto que. ROCHA LIMA (1999) não admite outra forma de oração de exceção, além da reduzida de infinitivo. CUNHA e CINTRA (2001, p. 590), por sua vez, afirmam que há muitas conjunções compostas por advérbios, preposições e particípios com a partícula que, formando as chamadas locuções conjuntivas. Todavia, eles não citam exceto que como uma delas, apesar de sua produtividade em língua portuguesa. Vejamos:

(17) O consulado do Brasil na China informou por meio de um e-mail que já entrou em contato com a agência de modelos, a qual já havia acionado a polícia. "Todos os modelos e demais habitantes do alojamento teriam sido interrogados pelos policiais. Ainda não está claro o que exatamente aconteceu, exceto que Camila teria caído pela janela do banheiro", diz o comunicado. (http://odia.ig.com.br/portal/ mundo/modelo-brasileira-\%C3\%A9-encontrada-morta-na-china-ap\%C3\%B3s-o-ano-novo-1.531243, acesso em 28/07/2015)

BECHARA (2015, p. 491) admite exceto que como um transpositor complexo de oração adverbial, como acontece nos dados do corpus. Esse tipo de composição sintagmática segue um modelo bastante produtivo em língua portuguesa, alinhado ao esquema X-que, em que um elemento (nominal, verbal ou adverbial) se combina com o elemento que.

LIMA-HERNANDES (2010) defende que essa reanálise é resultado da pressão exercida pelos aspectos pragmáticos da interação comunicativa sobre os mecanismos de metonímia e metáfora. Ao longo da história da língua portuguesa, diversos conectivos foram sendo formados por meio da adjunção de nomes, verbos, preposições e advérbios ao que, considerado subordinador por excelência. Casos de exceto que comprovam que esse mecanismo de criação de novos conectivos permanece produtivo em língua portuguesa.

ROCHA LIMA (1999, p. 263), por sua vez, considera a oração adverbial de exceção apenas na forma reduzida, como exemplifica em Nada fazia exceto dormir. Essa, entretanto, não é uma posição comum entre os gramáticos de orientação normativa. CUNHA e CINTRA (2001), por exemplo, não abordam a oração reduzida de infinitivo seguida de exceto.

Segundo BECHARA (2015, p. 518), a oração de exceção é um dos tipos de orações reduzidas de infinitivo. Na ótica do gramático, as orações 
de exceção pertencem ao grupo de orações reduzidas fixas, ou seja, normalmente, não aparecem na forma desenvolvida. Ele exemplifica essas orações com o uso dos conectores em vez de e a não ser que, mas nega-lhes o estatuto de conjunção subordinativa.

Em nosso corpus de pesquisa, encontramos o padrão exceto + infinitivo, como exemplificamos a seguir:

(18) O governo provincial fez pouco, exceto culpar os outros, disse ele. "Pagamos tributos aos médicos e funcionários dos hospitais do governo que estão trabalhando sem parar, tratando uma infinidade de pacientes", disse. "O governo de Sindh não fez nada exceto culpar a K-electric pelas mortes". (http://odia.ig.com.br/noticia/mundoeciencia/2015-06-25/onda-de-calor-mata-mais-de-mil-e-acaba-espaco-em-necroterios-do-paquistao.html, acesso em 28/07/2015)

Os dados de nossa pesquisa comprovaram a asserção de BECHARA (2015, p. 542), para quem essas orações não são codificadas na forma finita. Trata-se, portanto, de um grupo especial de orações, com uma vinculação sintática particular em relação às demais.

Assim, concluímos essa breve exposição acerca das construções de exceção em língua portuguesa. Em linhas gerais, a multifuncionalidade, a versatilidade morfossintática e a flexibilidade semântica são pontos marcantes dessa construção.

\section{Considerações finais}

Neste trabalho, procuramos traçar, à luz da LFCU, um panorama do conector exceto (e formas compostas), analisando seus usos em um corpus de textos do domínio jornalístico, publicados entre 2010 e 2015. Apesar da parca literatura sobre as construções de exceção nas gramáticas tradicionais, confirmamos a hipótese de que o conector exceto é produtivo no português brasileiro, justificando a necessidade de uma descrição mais pormenorizada para o tema.

Ao analisarmos nosso corpus, verificamos a presença de sete padrões construcionais compostos pelo conector exceto. São três padrões não oracionais (exceto $+\mathrm{SN}$, exceto $+\mathrm{SPrep}$ e exceto $+\mathrm{SAdv}$ ) e quatro oracionais (exceto + quando, exceto + se, exceto + que e exceto + infinitivo), com particularidades no campo semântico.

Nas construções não oracionais, a tendência é que a construção de exceção seja "pura", ou seja, que não esteja adjungida a outras semânticas. Já com relação às construções oracionais, é muito comum que haja 
amálgama de matizes semânticos, como ficou comprovado na análise de dados. De fato, além da noção de exceção, encontramos nos dados o sentido de condição em exceto se e o sentido de condição e tempo, em exceto quando. Esses amálgamas revelam, com clareza, a gradiência gramatical e a instabilidade que caracterizam a língua em uso.

As constatações reveladas pela pesquisa possibilitam a esquematização de uma pequena rede das construções de exceção instanciadas por exceto, como a que segue:

Esquema 1 - Rede das construções de exceção instanciadas por exceto

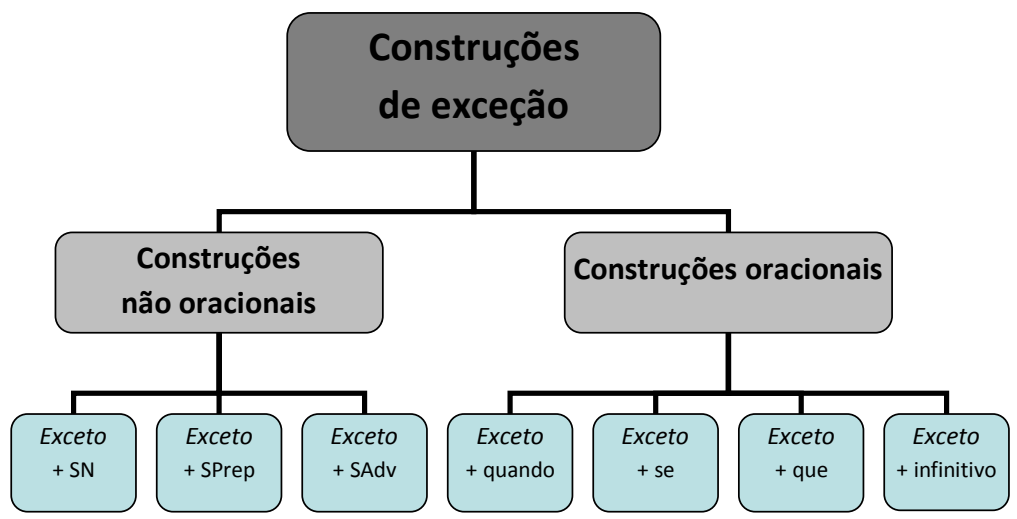

No campo das construções de exceção, ainda é necessário que haja mais refinamentos na descrição do plano semântico-pragmático, bem como uma ampliação do estudo com o foco de englobar outras configurações morfossintáticas, como as instanciadas por longe de, a não ser que etc. Esses são os próximos passos para desdobramentos futuros desta pesquisa.

Esperamos que os resultados obtidos nesta etapa do trabalho contribuam, principalmente, para a descrição do plano da conexão de orações, especialmente com relação àquelas orações cujas descrições ainda são parcas e lacônicas, como é o caso do âmbito da exceção. Por fim, assumindo o exceto como conector (nos níveis oracional e não oracional) e ampliamos o rol das construções hipotáticas em português, admitindo as orações adverbiais de exceção. 


\section{REFERÊNCIAS BIBLIOGRÁFICAS}

BECHARA, Evanildo. Moderna Gramática Portuguesa. 38. ed. Rio de Janeiro: Nova Fronteira, 2015.

CASTILHO, Ataliba de. Nova gramática do português brasileiro. São Paulo: Contexto, 2014.

CROFT, William. Radical Construction grammar: syntactic theory in typological perspective. Oxford: Oxford University Press, 2001.

CUENCA, Maria Joseph; HILFERTY, Joseph. Introducción a la linguística cognitiva. Barcelona: Ariel Linguística S.A., 1999.

CUNHA, Celso; CINTRA, Lindley. Nova gramática do português contemporâneo. 3. ed. Rio de Janeiro: Nova Fronteira, 2001.

CUNHA, Maria Angélica Furtado; BISPO, Edvaldo Balduino; SILVA, José Romerito. Linguística Funcional Centrada no Uso: conceitos básicos e categorias analíticas. In: CEZARIO, Maria Mauro; CUNHA, Maria Angélica Furtado. Linguística Centrada no Uso: uma homenagem a Mário Martelotta. Rio de Janeiro: Mauad x FAPERJ, 2013.

DECAT, Maria Beatriz. A articulação hipotática adverbial no português em uso. In:__ (Org). Aspectos da Gramática do Português: uma abordagem funcionalista. Campinas: Mercado das Letras, 2001.

GIVÓN, Talmy. Inter-clausal connections and discourse coherence. In:

English Grammar: a function-based introduction. vol. 2. John Benjamins Publishing Company: Amsterdam/Philadelphia, 1993.

GOLDBERG, Adele. Constructions: a construction grammar approach to argument structure. Chicago: The University Press, 1995.

. Constructions at work: the nature of generalization in language. Oxford: Oxford University Press, 2006.

; CASENHISER, Devin. English Constructions. In: AARTS, B; MCMAHON, A. Handbook of English Linguistics. USA, UK, Australia: Blackwell Publishers, 2010.

HOPPER, Paul. On some principles of grammaticalization. In: TRAUGOTT, E.; HEINE, B. Approaches to grammaticalization. vol. 1. Amsterdam: Benjamins, 1991.

KORTMANN, Bernd. Adverbial Subordination: a typology and history of adverbial subordinators based on European Languages. Berlin, New York: Mounton de Gruyter, 1997. 
LIMA-HERNANDES, Maria Célia. Processos sociocognitivos da mudança gramatical: estruturas X-que no português. Tese (Livre-docência) - Faculdade de Filosofia, Letras e Ciências Humanas, Departamento de Letras Clássicas e Vernáculas, Universidade de São Paulo, São Paulo, 2010.

MARTELOTTA, M. Mudança linguística: uma abordagem baseada no uso. São Paulo: Cortez, 2011.

MOURA NEVES, Maria Helena. A gramaticalização e a organização dos enunciados. SCRIPTA, Belo Horizonte, v. 5, n. 9, p. 13-22, $2^{\circ}$ semestre 2001. Disponível em: < http://www.ich.pucminas.br/cespuc/Revistas Scripta/Scripta09/ Conteudo/N09 Parte01 art01.pdf>. Acesso em: 10 dez. 2017.

. Gramática de usos de português. 2. ed. São Paulo: Unesp, 2011.

PRIBERAM. Dicionário de Língua Portuguesa. Disponível em: <www. priberam.pt/dlpo/>. Acesso em 26 fev. 2017.

REAL ACADEMIA ESPAÑOLA Y ASOCIACIÓN DE ACADEMIAS DE LA LENGUA ESPAÑOLA. Nueva Gramática de La Lengua Española. Manual. Madrid: Espasa, 2010.

ROCHA LIMA, Carlos Henrique. Gramática Normativa da Língua Portuguesa. 36. ed. Rio de Janeiro: José Olympio, 1999.

ROSÁRIO, Ivo da Costa do. Expressão da concessividade em construções do português do Brasil. Tese (Doutorado em Letras Vernáculas) - Universidade Federal do Rio de Janeiro, Rio de Janeiro, 2012.

. Sintaxe Funcional. In: OTHERO, Gabriel de Ávila; KENEDY, Eduardo. (Orgs.). Sintaxe, Sintaxes: uma introdução. 1 ${ }^{\mathrm{a}}$ ed. São Paulo: Contexto, 2015, p. 143-162.

; OLIVEIRA, Mariangela Rios. Funcionalismo e abordagem construcional da gramática. In: Alfa: Revista de Linguística (UNESP. Online), v. 60, p. 233-259, 2016. Disponível em http://www.scielo.br/pdf/alfa/ v60n2/1981-5794-alfa-60 -2-0233.pdf

TROUSDALE, Graeme. Constructions in grammaticalization and lexicalization: Evidence from the history of a composite predicate construction in English. In: Trousdale and Gisborne, eds. Constructional Approaches to English Grammar. Berlin: Mouton de Gruyter, 2008. p. 33-67.

Recebido em: 21/08/2018

Aceito em: 21/03/2019 